Check for updates

Cite this: RSC Adv., 2020, 10, 35302

Received 15th May 2020

Accepted 18th September 2020

DOI: $10.1039 / \mathrm{dOra04334f}$

rsc.li/rsc-advances

\section{Effect of chromium on the corrosion behaviour of low Cr-bearing alloy steel under an extremely high flow rate}

\begin{abstract}
Bei Wang, (D) ${ }^{a}$ Yun Wang, ${ }^{a}$ Qingping Li, ${ }^{b}$ Huixin Li, ${ }^{b}$ Lei Zhang (D) *a and Minxu Lu ${ }^{a}$
The effect of chromium on the corrosion behavior of low $\mathrm{Cr}$-bearing alloy steel in a wet gas pipeline with a high flow rate was studied using a rotating cylinder electrode (RCE) and self-built wet gas flow loop device. The results show that the addition of chromium in the steel can increase the flow accelerated corrosion (FAC) resistance of steel effectively. It was hard for pure $\mathrm{FeCO}_{3}$ to deposit onto the carbon steel surface to form an intact corrosion film when the flow rate or wall shear stress was high. However, a mixture of $\mathrm{Cr}(\mathrm{OH})_{3}$ and $\mathrm{FeCO}_{3}$ can still be deposited onto the $3 \mathrm{Cr}$ steel surface and form an intact and protective corrosion film even under conditions with a $212 \mathrm{~Pa}$ wall shear stress in the wet gas pipeline.
\end{abstract}

\section{Introduction}

Carbon steel is the most widely used material in the natural gas industry. However, with the development of natural gas extraction, injection, and transportation technology, the natural gas flow rate in some areas has reached a high level. Under the combined action of corrosive substances such as $\mathrm{CO}_{2}, \mathrm{H}_{2} \mathrm{~S}$, and $\mathrm{Cl}^{-}$, carbon steel is faced with severe flow accelerated corrosion (FAC) problems. ${ }^{1-4}$ FAC is a deterioration action due to the effect of fluid flow that leads to the destruction or thinning of pipelines. ${ }^{5,6}$ FAC depends on hydrodynamic parameters of the fluid flow, such as flow rate and wall shear stress. ${ }^{7}$ High flow rate and wall shear stress lead to efficient mixing, which prevents the formation of protective films on the surface of the pipeline and increases the corrosion rate as a result. ${ }^{8}$ FAC has caused a large number of failures in piping and equipment in all types of fossil, industrial steam, and nuclear power plants, and it is a predominant mode of failure of pipelines. ${ }^{9}$

As a countermeasure, replacement of the carbon steel with low Cr-bearing alloy steel, which boasts an excellent performance to price ratio and improved $\mathrm{CO}_{2}$ corrosion resistance, has been suggested because trace amounts of $\mathrm{Cr}$ element can effectively prevent FAC. ${ }^{\mathbf{1 0 - 1 2}}$ Jiang et al. ${ }^{\mathbf{1 3 , 1 4}}$ reported that the addition of $\mathrm{Cr}$ generates amorphous products in a rust layer, and $\mathrm{Cr}$ is suitable for improving the corrosion resistance of low alloy steel to flow-accelerated corrosion caused by the inhibition of a cathodic reaction in an $\mathrm{O}_{2}$-containing environment. A large number of studies have shown that the amorphous product film will form on the surface of low $\mathrm{Cr}$ steel, with fewer pores and better protection. ${ }^{\mathbf{1 5 - 1 7}}$ However, there is still a lack of research on

${ }^{a}$ University of Science and Technology Beijing, Beijing 100083, China. E-mail: zhanglei@ustb.edu.cn

${ }^{b}$ CNOOC Research Institute, Beijing, 100028, China

the FAC of Cr-bearing alloy steel in the $\mathrm{CO}_{2}$-containing environment. Wang et al. ${ }^{18}$ found that pitting corrosion of $1 \mathrm{Cr}$ and $3 \mathrm{Cr}$ steel may occur under the flow conditions with sand. Stack et $a{ }^{19}{ }^{19}$ found that increases in flow velocity resulted in higher current densities for the anodic reaction. Flow rate has a significant effect on the precipitation kinetics, morphology, and mechanical properties of a $\mathrm{FeCO}_{3}$ scale on carbon steel. ${ }^{20-22}$ However, few investigations have been conducted on the effect of flow on the corrosion product performance of low Cr-bearing alloy steel in the $\mathrm{CO}_{2}$-containing environment.

Presently, most research on FAC is generally carried out under the liquid phase and focused on the nuclear power plant pipeline. ${ }^{23-28}$ However, FAC in the natural gas pipeline usually occurs in the wet gas medium, and its corrosion environment is very different from that in the liquid phase. ${ }^{29-31}$ Traditional laboratory liquid phase corrosion simulation methods may not be able to obtain the actual corrosion resistance and corrosion resistance mechanism of the material in the wet gas medium.

Therefore, in this study, the corrosion resistance and corrosion mechanism of carbon steel and $3 \mathrm{Cr}$ steel under high flow rate and high wall shear stress conditions were studied by combining the traditional experimental method and the selfbuilt wet gas flow loop. The results of this research have essential engineering significance for the extension of $3 \mathrm{Cr}$ steel and the control of FAC in the natural gas pipeline.

Table 1 Chemical composition of carbon steel and $3 \mathrm{Cr}$ steel (wt\%)

\begin{tabular}{llllllll}
\hline Materials & $\mathrm{C}$ & $\mathrm{Cr}$ & $\mathrm{Mo}$ & $\mathrm{Si}$ & $\mathrm{Mn}$ & $\mathrm{Nb}$ & $\mathrm{Fe}$ \\
\hline Carbon steel & 0.05 & - & 0.16 & 0.17 & 1.51 & 0.04 & Bal. \\
$3 \mathrm{Cr}$ & 0.07 & 2.96 & 0.15 & 0.20 & 0.55 & 0.03 & Bal.
\end{tabular}


Table 2 Composition of the RCE test solution $\left(\mathrm{mg} \mathrm{L}^{-1}\right)$

\begin{tabular}{llllll}
\hline Composition & $\mathrm{NaCl}$ & $\mathrm{MgCl}_{2} \cdot 6 \mathrm{H}_{2} \mathrm{O}$ & $\mathrm{CaCl}_{2}$ & $\mathrm{KCl}$ & $\mathrm{NaHCO}_{3}$ \\
Concentration & 25318.99 & 1920.03 & 2747.25 & 643.75 & 519.15
\end{tabular}

Table 3 Composition of the flow loop test solution ( $\mathrm{mg} \mathrm{L}^{-1}$ )

\begin{tabular}{lll}
\hline Composition & $\mathrm{NaCl}$ & $\mathrm{CaCl}_{2}$ \\
Concentration & 300 & 350
\end{tabular}

\section{Experiment}

\section{Material and solution}

The materials used here were carbon steel and $3 \mathrm{Cr}$ steel with chemical compositions (wt\%) listed in Table 1 . The specimens were ground to 800 grit and then cleaned with distilled water and alcohol. The composition of the RCE test and flow loop test solutions are shown in Tables 2 and 3, respectively. Before the test, the solutions were first deaerated by pure $\mathrm{CO}_{2}$.

\section{RCE test}

The RCE is an ideal tool for studying turbulent flow. Higher turbulent velocities are easily accessible at higher rotation rates. Fig. 1 shows a schematic diagram of the RCE. All electrochemical measurements were performed in a glass cell with a traditional three-electrode system using a Gamry Reference600+ electrochemical workstation. The volume of the solution used was $1 \mathrm{~L}$. The working electrodes were carbon steel and $3 \mathrm{Cr}$ steel rotating cylinders, $12 \mathrm{~mm}$ diameter, $8 \mathrm{~mm}$ long, and $3 \mathrm{~cm}^{2}$ electrode surface area. A platinum sheet was used as a counter electrode, and a saturated calomel electrode (SCE) was used as a reference electrode.

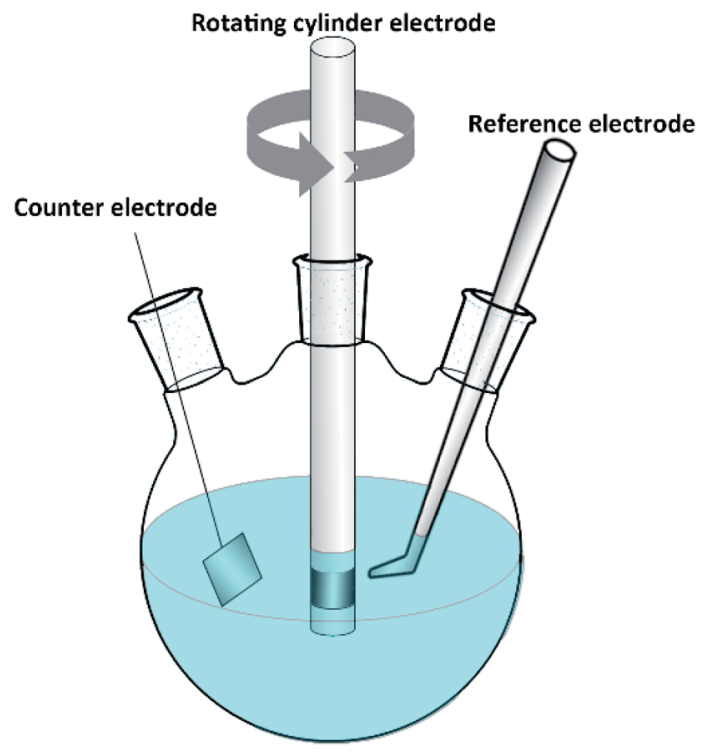

Fig. 1 Schematic of the rotating cylinder electrode tests.
The electrochemical impedance spectroscopy (EIS) measurements were performed using the AC signals of the $10 \mathrm{mV}$ peak-to-peak amplitude at the OCP in the frequency range of $100 \mathrm{kHz}$ to $5 \mathrm{mHz}$.

\section{Flow loop test}

A schematic diagram of the flow loop is shown in Fig. 2. The flow loop is a $25 / 50 \mathrm{~mm}$ diameter, high-pressure system. The entire flow loop is manufactured from $316 \mathrm{~L}$ stainless steel. The flow loop was driven by a circulating fan. The solution was dosed into the flow loop by a continuous dosing device and mixed with the high flow rate $\mathrm{CO}_{2}$ gas. The coupon was a disc with a diameter of $16 \mathrm{~mm}$ and a thickness of $3 \mathrm{~mm}$. Three coupons were installed in the test section. A cooling casing is installed outside the test section to control the temperature of the system. Downstream of this test section, a gas-liquid separator was used to separate the liquids and gas. After gasliquid separation, the gas phase continues to circulate in the loop, and the liquid phase is discharged to the outside. The parameters of the flow loop tests are shown in Table 4.

The corrosion rate was measured using the weight-loss method. The morphology and energy dispersive X-ray spectroscopy (EDS) analysis of the corrosion scale were investigated using a JSM-6510A SEM and a JED-2300 EDS. The X-ray photoelectron spectroscopy (XPS) of the corrosion scale was examined using a Thermo Escalab 250Xi instrument.

\section{Results}

\section{RCE test}

For typical RCE devices, the transition from laminar to turbulent flow occurs when the Reynolds number exceeds 200 . Because this transition occurs at a relatively low rotation rate, the RCE is considered an ideal tool for studying turbulent flow at a low velocity, which is a condition frequently observed in pipeline infrastructures. Moreover, higher turbulent velocities are easily achievable at higher rotation rates.

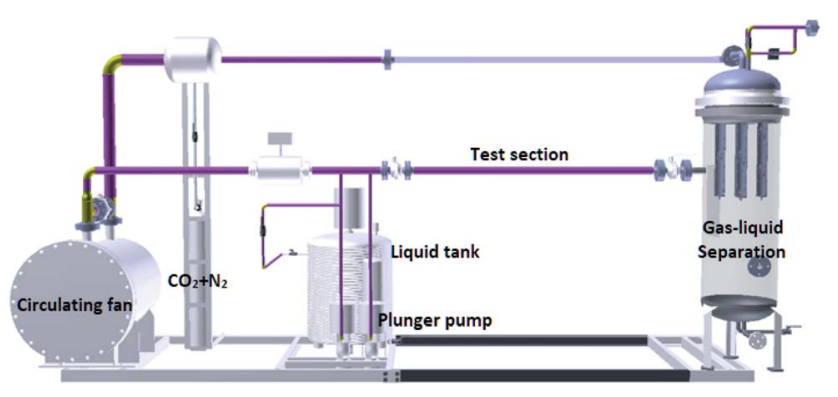

Fig. 2 Schematic of the flow loop tests. 
Table 4 Parameters of the flow loop tests

\begin{tabular}{|c|c|c|c|c|c|c|c|}
\hline No. & $T /{ }^{\circ} \mathrm{C}$ & $P / \mathrm{MPa}$ & $P_{\mathrm{CO}_{2}} / \mathrm{MPa}$ & Water cut $/ \%$ & Gas velocity $/ \mathrm{ms}^{-1}$ & $t / \mathrm{h}$ & Shear stress $/ \mathrm{Pa}$ \\
\hline 1 & 60 & 0.42 & 0.42 & 0.000100 & 21.0 & 48 & 16.2 \\
\hline 2 & 60 & 0.43 & 0.43 & 0.000235 & 31.4 & 48 & 29.3 \\
\hline 4 & 60 & 1.00 & 1.00 & 0.000100 & 17.6 & 48 & 19.9 \\
\hline 5 & 60 & 0.52 & 0.52 & 0.000615 & 17.6 & 48 & 22.9 \\
\hline 6 & 60 & 0.52 & 0.52 & 0.001000 & 40.0 & 72 & 56.0 \\
\hline 9 & 60 & 1.00 & 0.52 & 0.000615 & 40.0 & 48 & 111 \\
\hline 10 & 60 & 1.70 & 0.52 & 0.000615 & 31.4 & 48 & 212 \\
\hline
\end{tabular}

The corrosion of 3Cr steel and carbon steel under different rotation rates was periodically investigated through EIS. EIS measurements can provide insight into the change of corrosion film characteristics and the corrosion process occurring at the interface. Fig. 3a presents the Nyquist diagrams of carbon steel obtained at $2000 \mathrm{rpm}$ after immersion for 1, 3, 5, 9, 12, 18, and $24 \mathrm{~h}$, with the characteristics of a capacitance loop and an inductive loop. The impedance increased slowly, which means the product film grows slowly, and the corrosion rate decreases slowly. A distinct inductive loop in the low frequency was always present. The low-frequency inductive loop is associated with the adsorption of the intermediate product on the substrate surface. It indicated that a corrosion film was barely formed on the carbon steel surface at a high flow rate. The adsorption and desorption of intermedia products on the steel surface were extremely high.

Fig. $3 \mathrm{~b}$ presents the Nyquist diagrams of $3 \mathrm{Cr}$ steel obtained at $1000 \mathrm{rpm}$ after immersion for $1,3,5,9,12,18$, and $24 \mathrm{~h}$, with the characteristics of two typical capacitance loops and an inductive loop. The impedance gradually increased, which was attributed to corrosion scale growth on the substrate. Initially, the inductive loop expanded and then shrank. The inductive loop was closely related to the adsorption and desorption of intermediate products. In the initial stage, the corrosion film coverage was low, and the formation of intermediate products such as $\mathrm{FeOH}_{\mathrm{ad}}$ and $\mathrm{CrOH}_{\mathrm{ad}}$ increased with time. The adsorption and desorption of intermediate products on the steel surface became stronger. Subsequently, as corrosion proceeded, the coverage of the corrosion film increased, and the adsorption and desorption of intermediate products on the steel surface weakened.

Fig. 3c presents the Nyquist diagrams of $3 \mathrm{Cr}$ steel obtained at $2000 \mathrm{rpm}$ after $1,3,5,9,12,18$, and $24 \mathrm{~h}$ of immersion, with the characteristics of two typical capacitance loops and an inductive loop. Initially, the impedance increased and then shrank, and the inductive loop gradually increased. In the initial stage, the corrosion products deposited on the steel surface and corrosion film coverage increased. When corrosion proceeded, the corrosion film was destroyed because of the high flow rate. Moreover, the formation of intermedia products increased with time, and the adsorption and desorption of intermedia products became stronger.

Fig. 4 illustrates equivalent circuits for EIS fitting. $R_{\mathrm{S}}, \mathrm{CPE}_{\mathrm{film}}$, and $R_{\text {pore }}$ denote the electrolyte solution resistance, constant phase element (CPE) used to fit the corrosion film capacitance, and resistance of the pores in the corrosion film, respectively. Electrochemical processes at the interface are represented by $R_{\mathrm{ct}}$ and $\mathrm{CPE}_{\mathrm{dl}}$, which denote the charge transfer resistance and electric double-layer capacitance, respectively. $Y_{\mathrm{o}}$ and $n$ were the parameters obtained using the constant phase element. $R_{\mathrm{L}}$ and $L$ were the inductive resistance and inductance, respectively. Table 5 presents the results. The polarisation resistance $\left(R_{\mathrm{p}}\right)$, that is, the sum of $R_{\text {pore }}$ and $R_{\mathrm{ct}}$, was inversely proportional to the corrosion rate. For carbon steel or low Cr-bearing alloy steel, the corrosion medium can react with steel through pores present on a protective scale, and dissolved $\mathrm{Fe}^{2+}$ can exit the
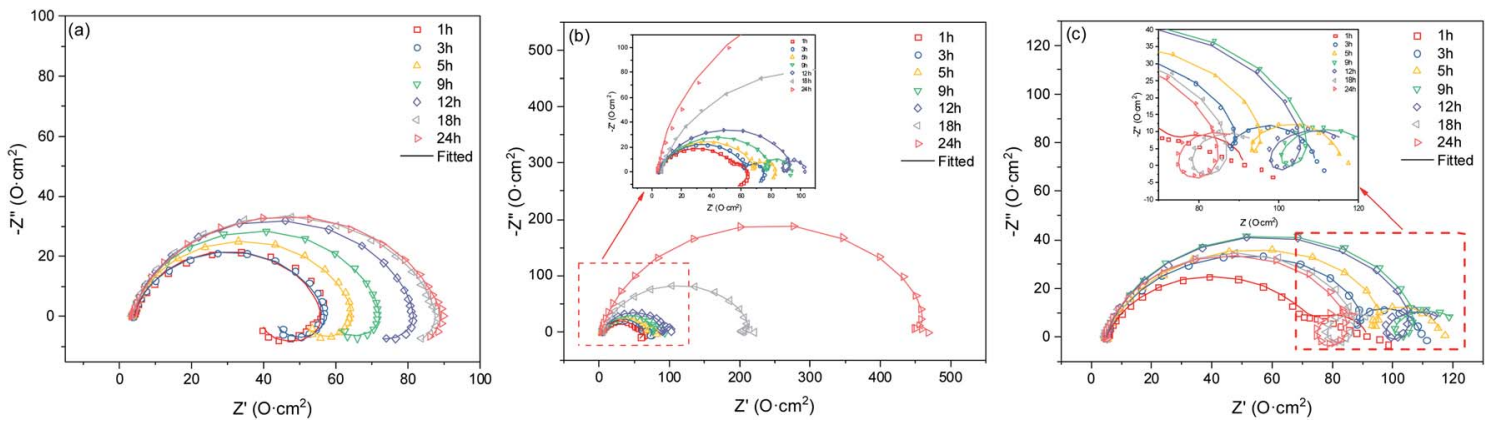

Fig. 3 Nyquist diagrams (a) carbon steel, 2000 rpm; (b) 3Cr steel, 1000 rpm; (c) 3Cr steel, 2000 rpm. 

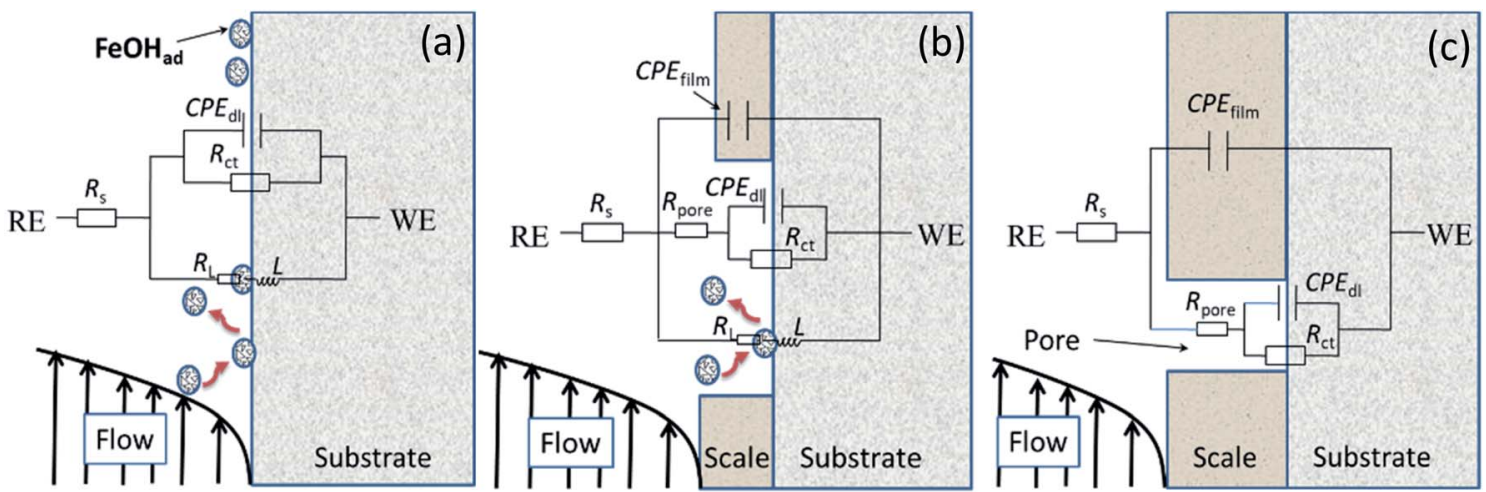

Fig. 4 Equivalent circuits used for modeling the EIS results in Fig. 3.

Table 5 Values of the elements of the equivalent circuit in Fig. 4 to fit the impedance spectra of Fig. 3

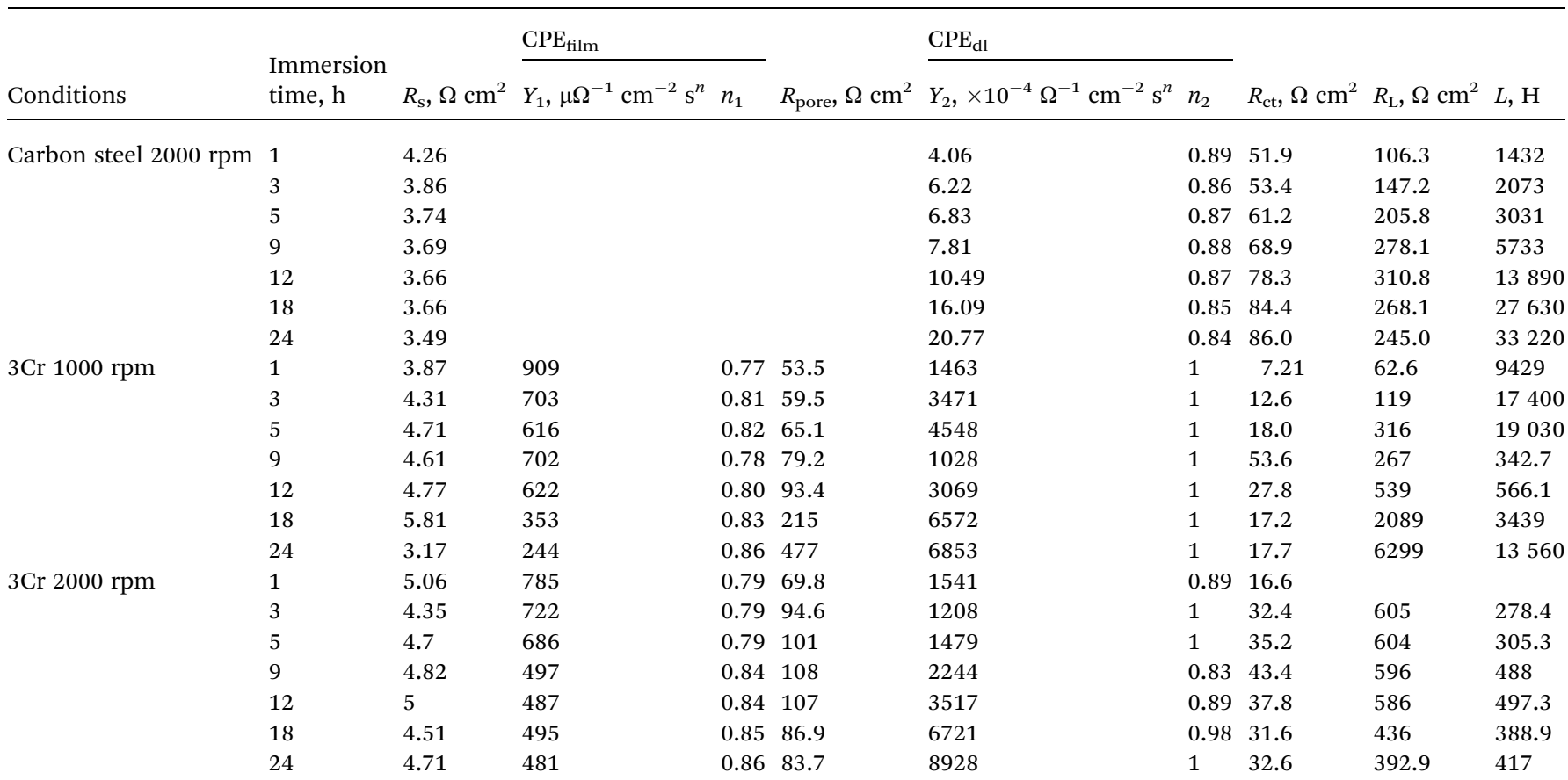

pores. Thus, protecting the corrosion scale is closely associated with the $R_{\text {pore }}$ Fig. 5 presents $R_{\text {pore }}$ and $R_{\mathrm{p}}$ obtained from Table 5 .

The $R_{\mathrm{p}}$ value of carbon steel at $2000 \mathrm{rpm}$ was considerably low and slowly increased with time, indicating that the corrosion film may form only negligibly on the steel surface. For $3 \mathrm{Cr}$ steel at $2000 \mathrm{rpm}, R_{\mathrm{p}}$ and $R_{\text {pore }}$ increased first and then decreased, which was attributed to the formation and destruction of the corrosion film. The $R_{\mathrm{p}}$ of $3 \mathrm{Cr}$ steel was considerably higher than that of carbon steel, which revealed that the corrosion resistance of $3 \mathrm{Cr}$ steel at a high flow rate was substantially stronger than that of carbon steel. When the rotation speed decreased to $1000 \mathrm{rpm}, R_{\mathrm{p}}$ and $R_{\text {pore }}$ sharply increased with time. In the initial stage (1-12 h), the value was lower than that at $2000 \mathrm{rpm}$, which indicated that the high flow rate could accelerate the formation of considerably more protective corrosion films on the $3 \mathrm{Cr}$ steel surface. After $12 \mathrm{~h}$, the value at $1000 \mathrm{rpm}$ rapidly exceeded that at $2000 \mathrm{rpm}$. This finding revealed that the rotation speed of $1000 \mathrm{rpm}$ posed no threat to the corrosion film. At a high flow rate, $3 \mathrm{Cr}$ steel exhibited substantially better flow accelerated corrosion resistance than carbon steel did.

The EIS results indicated that the addition of $\mathrm{Cr}$ improved the corrosion resistance of steel, mainly because Cr positively influences the deposition of a corrosion film on steel at a high flow rate. Therefore, to further confirm the aforementioned conjugation, SEM and EDS analyses were conducted, and the results are presented in Fig. 6.

For carbon steel, the SEM results revealed no prominent corrosion film on the steel surface. The EDS results indicated that the $\mathrm{O}$ and $\mathrm{Fe}$ concentrations were considerably lower and higher, respectively, in carbon steel than in $3 \mathrm{Cr}$ steel. This 

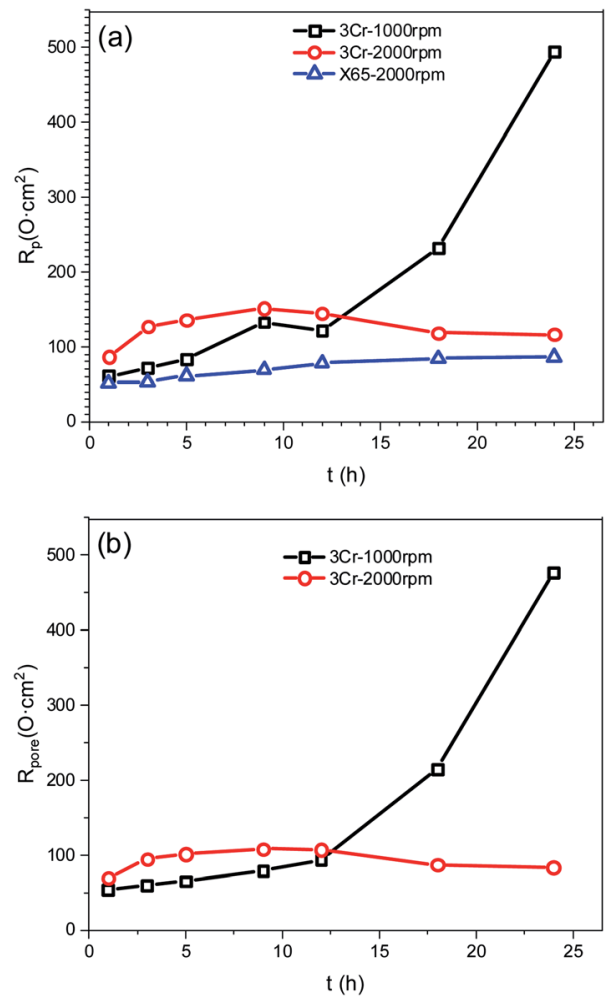

Fig. 5 The $R_{\text {pore }}$ value (a) and $R_{\mathrm{p}}$ value (b) obtained from the EIS results.

finding indicated that $\mathrm{FeCO}_{3}$ rarely deposited on the surface of steel under the condition of the high flow rate. The results are consistent with those presented in Fig. 3a.

For $3 \mathrm{Cr}$ steel, the surface was covered with the cracked corrosion film deposited at 1000 and $2000 \mathrm{rpm}$. The EDS results revealed that the corrosion film was $\mathrm{Cr}$-enriched, indicating that the main components of the corrosion product film were $\mathrm{Cr}(\mathrm{OH})_{3}$ and $\mathrm{FeCO}_{3}$. The corrosion film can provide excellent protection for $3 \mathrm{Cr}$ steel at a high flow rate. In the produced film, the ratio of $\mathrm{Cr} / \mathrm{Fe}$ at $1000 \mathrm{rpm}$ was slightly higher than that at $2000 \mathrm{rpm}$, and the oxygen content was slightly higher at $2000 \mathrm{rpm}$ than that at $1000 \mathrm{rpm}$. This may be because the corrosion rate at $2000 \mathrm{rpm}$ was higher than that at $1000 \mathrm{rpm}$, which led to the generation of more $\mathrm{Fe}^{2+}$. Finally, the content of $\mathrm{FeCO}_{3}$ deposited on the corrosion film increased, and the corrosion film became thicker.

The corrosion film on the surface was complete without any damage at $1000 \mathrm{rpm}$, and at $2000 \mathrm{rpm}$, most of the corrosion film on the surface was complete, but some areas of the corrosion film were damaged.

This finding is consistent with the EIS results, that is, when the flow rate was $1000 \mathrm{rpm}$, the corrosion film on the surface grew steadily with time and exhibited excellent flow accelerated corrosion resistance, which was not damaged by fluids under this working condition.

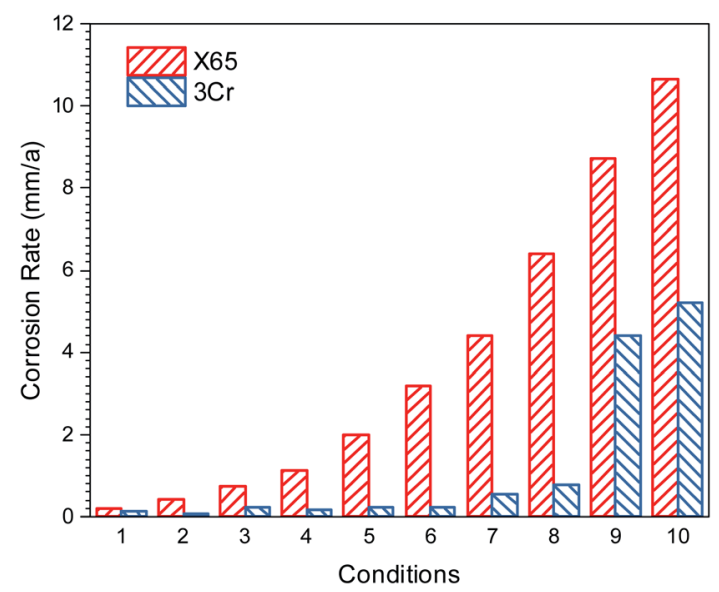

Fig. 7 Corrosion rate of carbon steel and $3 \mathrm{Cr}$ steel measured under different conditions in Table 4.
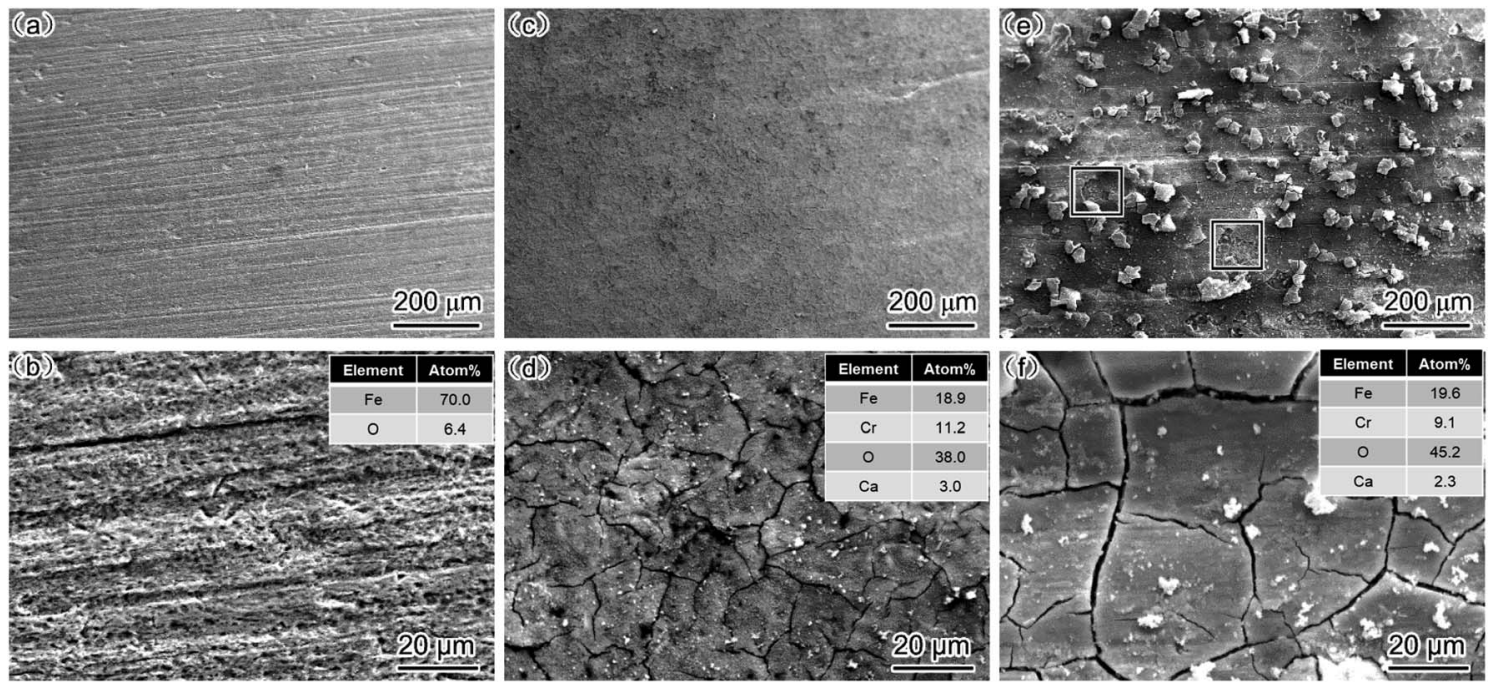

Fig. 6 SEM-SE image and EDS analysis of corrosion scale (a and b) carbon steel, 2000 rpm; (c and d) 3Cr steel, 1000 rpm; (e and f) 3Cr steel, $2000 \mathrm{rpm}$. 

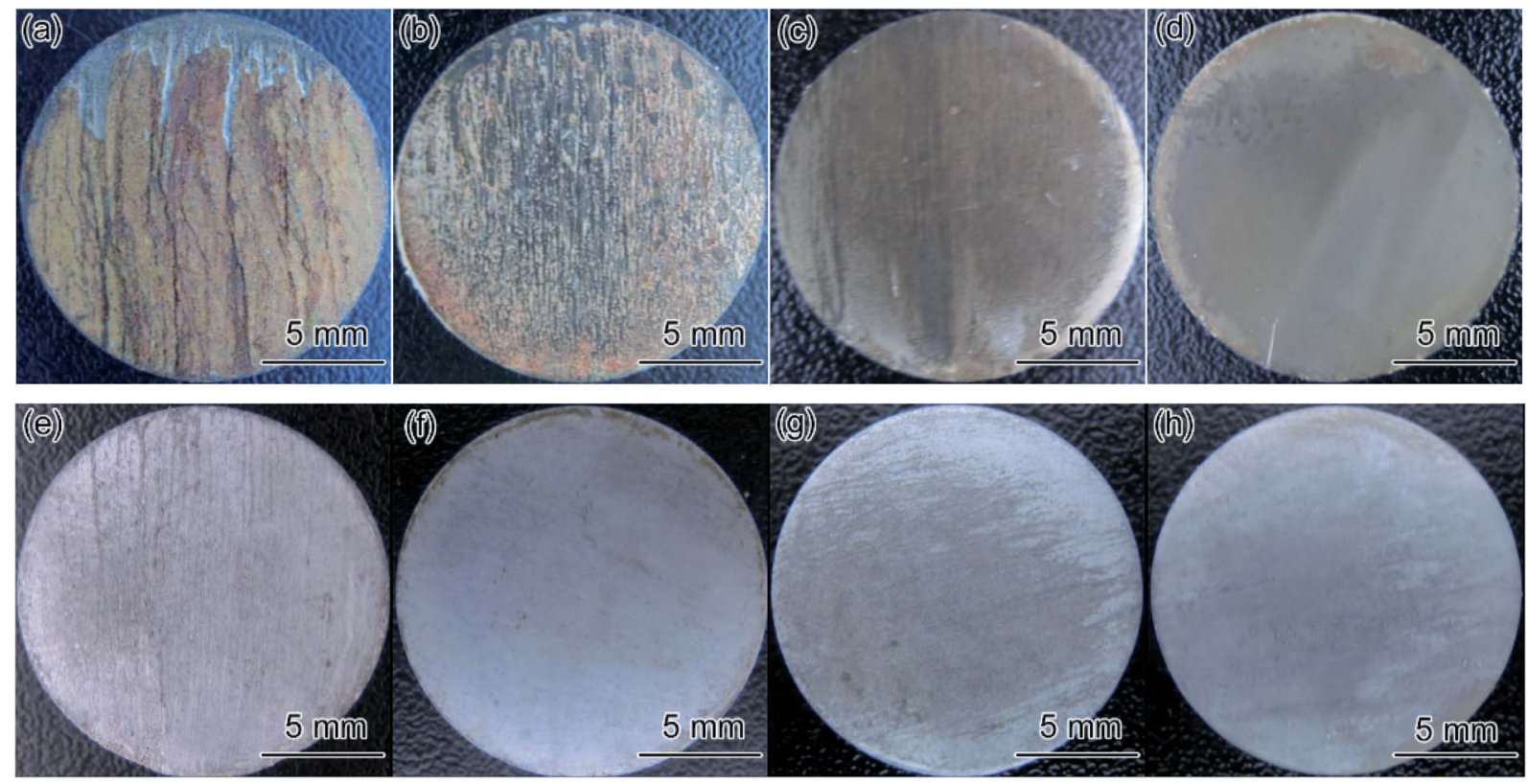

Fig. 8 Macro morphologies of coupons with $(a-d)$ and without $(e-h)$ the corrosion film after flow loop tests under conditions 5 and 6 in Table 4 : ( $a$ and e) carbon steel, 24 h; (b and f) carbon steel, 72 h; (c and g) 3Cr steel, 24 h; ( $d$ and h) $3 \mathrm{Cr}$ steel, 72 h.

When the rotation rate increased to $2000 \mathrm{rpm}$, the severe turbulence damaged the corrosion film. However, because most areas of the steel surface were covered with the complete corrosion film, the corrosion resistance of $3 \mathrm{Cr}$ steel remained considerably higher than that of carbon steel, which cannot form a continuous corrosion film.

\section{Flow loop test}

The results of the RCE experiment indicated that adding $\mathrm{Cr}$ can enhance the corrosion resistance of steel at a high flow rate. Furthermore, to confirm the excellent flow accelerated corrosion resistance of low Cr-containing alloy steel at a high flow rate and its corrosion resistance mechanism, flow loop tests were conducted, which can simulate actual conditions in the wet gas pipeline.

Fig. 7 presents the corrosion rate of carbon steel and $3 \mathrm{Cr}$ steel measured under different conditions by conducting flow loop tests. The flow accelerated corrosion resistance of $3 \mathrm{Cr}$ steel was considerably better than that of carbon steel under wet gas conditions at a high flow rate.

Fig. 8 illustrates the macro morphologies of coupons with and without the corrosion film after 24 and $72 \mathrm{~h}$ flow loop tests under conditions 5 and 6 in Table 4 . The corrosion film on carbon steel coupons exhibited obvious damage along the direction of fluid flow, resulting in some matrices being exposed, and the surface of $3 \mathrm{Cr}$ steel was covered with a complete corrosion product film. The result indicated that the corrosion film formed on the $3 \mathrm{Cr}$ steel surface exhibited considerably better flow accelerated corrosion resistance than that formed on the carbon steel surface did.

Fig. 9 shows the surface morphology of corrosion film on the carbon steel and $3 \mathrm{Cr}$ steel surface after $72 \mathrm{~h}$ corrosion in the flow loop tests under condition 6 . The corrosion film of carbon steel showed an obvious sign of being damaged by fluid erosion. However, the corrosion film of $3 \mathrm{Cr}$ steel was intact, and some cracks formed on the entire surface because of dehydration. ${ }^{15,32}$
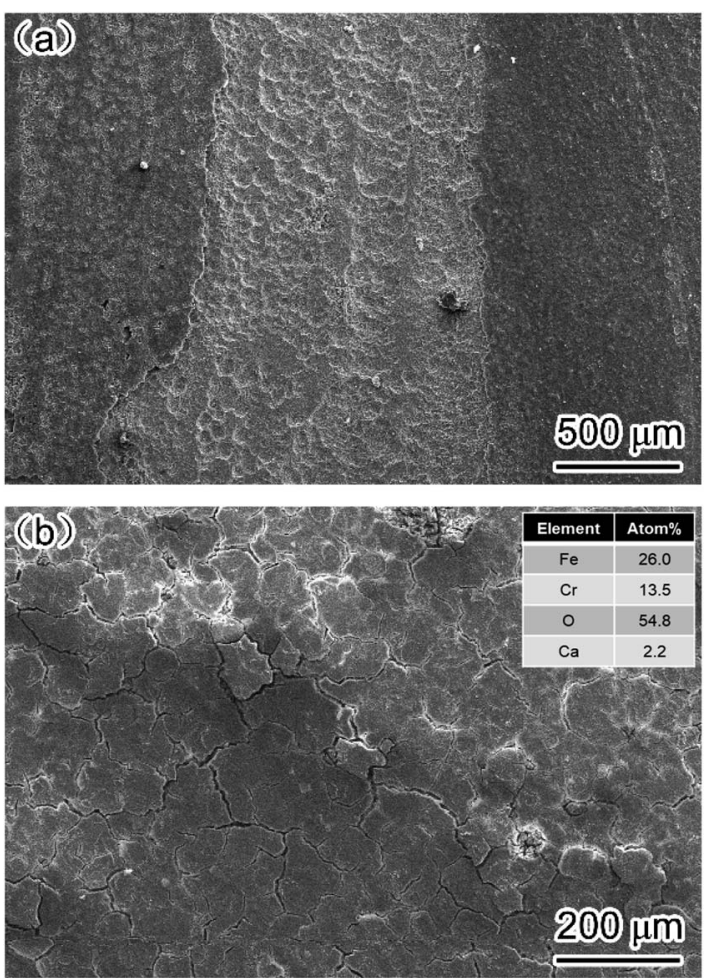

Fig. 9 SEM-SE image of corrosion film on (a) carbon steel and (b) $3 \mathrm{Cr}$ steel after flow loop tests under condition 6 in Table 4. 

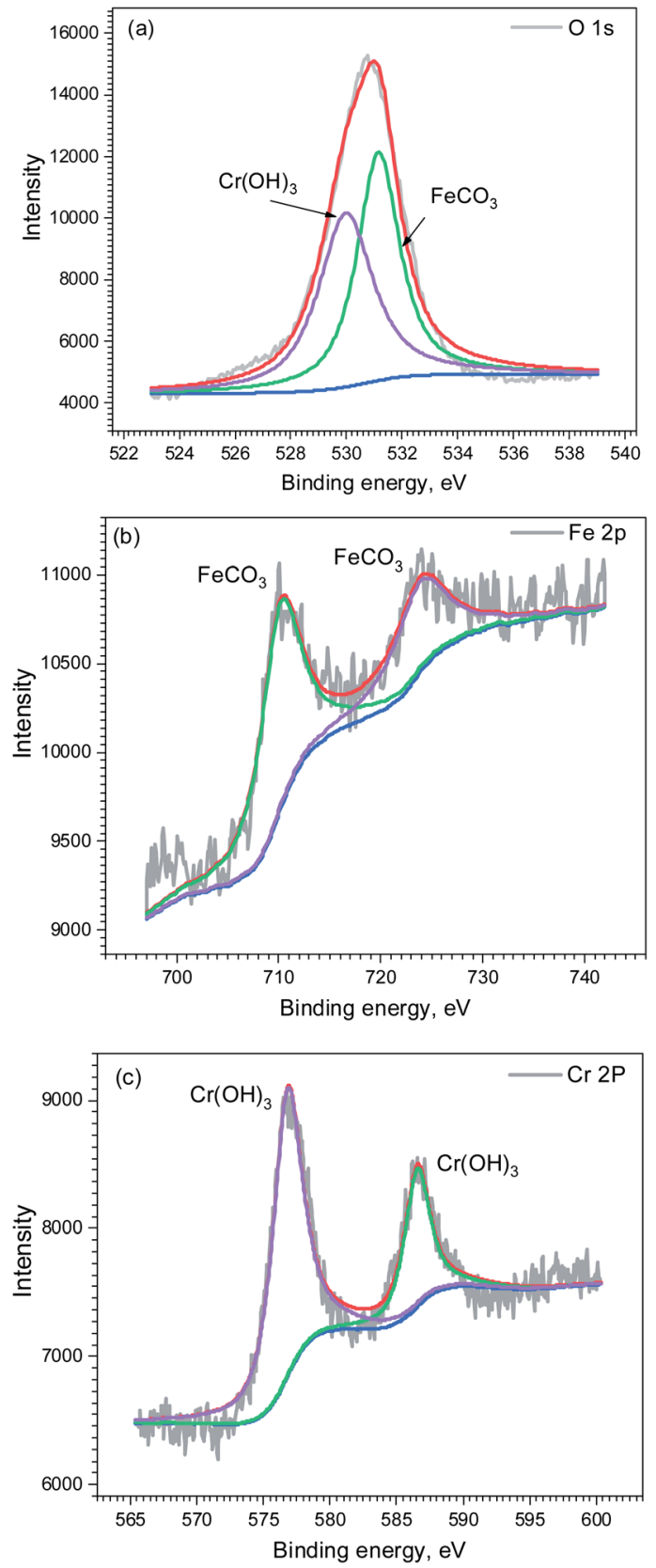

Fig. 10 XPS analysis of corrosion scale formed on $3 \mathrm{Cr}$ steel surface after flow loop tests under condition 6 in Table 4: (a) O 1s; (b) Fe 2p 2/3; (c) $\mathrm{Cr} 2 \mathrm{p}_{2 / 3}$.

The EDS results indicated that the corrosion film of $3 \mathrm{Cr}$ steel was rich in Cr. Furthermore, to determine the composition of the corrosion product film, the corrosion film was analyzed through XPS; Fig. 10 presents the results. The XPS results revealed that the corrosion film mainly comprises $\mathrm{Cr}(\mathrm{OH})_{3}$ and $\mathrm{FeCO}_{3}$.

Furthermore, the corrosion films formed on X65 and $3 \mathrm{Cr}$ steel in the flow loop under the condition of the highest wall shear stress were analyzed through SEM and EDS. The carbon steel matrix exhibited a crater-like surface, and no prominent corrosion film was observed, which indicated that it is difficult
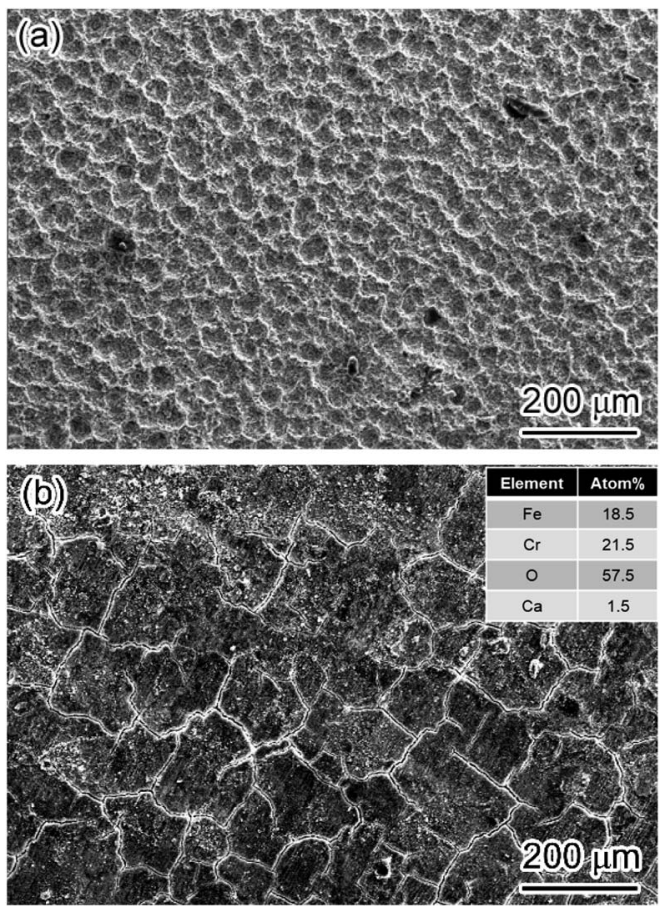

Fig. 11 SEM-SE image of corrosion film on $3 \mathrm{Cr}$ steel after flow loop tests under condition 10 in Table 4. (a) Carbon steel, (b) $3 \mathrm{Cr}$ steel.

for $\mathrm{FeCO}_{3}$ deposited onto the steel surface to form an intact corrosion film (Fig. 11a). However, a mixture of $\mathrm{Cr}(\mathrm{OH})_{3}$ and $\mathrm{FeCO}_{3}$ could still be deposited on the $3 \mathrm{Cr}$ steel surface and form an intact and protective corrosion film even under the conditions of $212 \mathrm{~Pa}$ wall shear stress (Fig. 11b), indicating that $\mathrm{Cr}(\mathrm{OH})_{3}$ can improve the shear resistance of corrosion films.

\section{Conclusions}

The effect of chromium on the corrosion behaviour of low $\mathrm{Cr}-$ bearing steel under a high flow rate or wall shear stress was studied using RCE and flow loop tests. The main conclusions are as follows:

(1) The flow accelerated corrosion resistance of $3 \mathrm{Cr}$ steel is considerably better than that of carbon steel under a high flow rate, especially in a wet gas environment. Adding chromium to steel can effectively increase its flow accelerated corrosion resistance.

(2) It is difficult for pure $\mathrm{FeCO}_{3}$ deposited onto the carbon steel surface to form an intact corrosion film at a high flow rate. However, a mixture of $\mathrm{Cr}(\mathrm{OH})_{3}$ and $\mathrm{FeCO}_{3}$ could still be deposited on the $3 \mathrm{Cr}$ steel surface and form an intact and protective corrosion film even under the conditions of $212 \mathrm{~Pa}$ wall shear stress, indicating that $\mathrm{Cr}(\mathrm{OH})_{3}$ can improve the shear resistance of corrosion films.

\section{Conflicts of interest}

There are no conflicts to declare. 


\section{Acknowledgements}

The project supported by China Postdoctoral Science Foundation (Grant No. 2019M660454) and National Science and Technology Major Project of China (Grant No. 2016ZX05028004).

\section{Notes and references}

1 G. A. Zhang and Y. F. Cheng, Corros. Sci., 2010, 52, 27162724.

2 G. A. Zhang, L. Zeng, H. L. Huang and X. P. Guo, Corros. Sci., 2013, 77, 334-341.

3 X. Jiang, Y. G. Zheng and W. Ke, Corros. Sci., 2005, 47, 26362658.

4 A. Prethaler, G. Mori and E. Rosenberg, BHM BergHüttenmännische Monatsh., 2015, 160, 346-351.

5 R. B. Dooley and V. K. Chexal, Int. J. Pressure Vessels Piping, 2000, 77, 85-90.

6 Y. Xu and M. Y. Tan, Corros. Sci., 2019, 151, 163-174.

7 T. S. Ajmal, S. B. Arya and K. R. Udupa, Int. J. Pressure Vessels Piping, 2019, 174, 42-53.

8 A. A. Abd, S. Z. Naji and A. S. Hashim, Eng. Failure Anal., 2019, 105, 638-646.

9 V. Kain, Procedia Eng., 2014, 86, 576-588.

10 S. Kim, T. Kim, Y. Lee and J. H. Kim, Corros. Sci., 2019, 159, 108143.

11 M. N. Zafar, R. Rihan and L. Al-Hadhrami, Corros. Sci., 2015, 94, 275-287.

12 S. Hassani, T. N. Vu, N. R. Rosli, S. N. Esmaeely, Y. S. Choi, D. Young and S. Nesic, Int. J. Greenhouse Gas Control, 2014, 23, 30-43.

13 S. Jiang, F. Chai, H. Su and C. F. Yang, Corros. Sci., 2017, 123, 217-227.

14 F. Chai, S. Jiang and C. Yang, J. Iron Steel Res. Int., 2016, 23, 602-607.
15 S. Guo, L. Xu, L. Zhang, W. Chang and M. Lu, Corros. Sci., 2016, 110, 123-133.

16 J. Zhu, L. Xu, M. Lu, L. Zhang, W. Chang and L. Hu, Corros. Sci., 2015, 93, 336-340.

17 B. Wang, L. Xu, J. Zhu, H. Xiao and M. Lu, Corros. Sci., 2016, 111, 711-719.

18 W. Yan, J. Deng, X. Li, X. Dong and C. Zhang, Chin. Sci. Bull., 2012, 57, 927-934.

19 M. M. Stack, J. S. James and Q. Lu, Wear, 2004, 256, 557-564.

20 R. A. De Motta, A Combined Experimental and Modelling Approach to Elucidate $\mathrm{FeCO}_{3}$ Scale Formation Kinetics, University of Leeds, 2016.

21 S. Nešić, Corros. Sci., 2007, 49, 4308-4338.

22 Y. Yang, B. Brown, S. Nešić, M. E. Gennaro and B. Molinas, Corrosion, 2010, 10383.

23 Y. Utanohara and M. Murase, Nucl. Eng. Des., 2019, 342, 2028.

24 G. V. Tomarov, A. A. Shipkov and T. N. Komissarova, Therm. Eng., 2019, 66, 138-147.

25 Y. Bandla and S. K. Thamida, J. Fail. Anal. Prev., 2019, 19, 17.

26 M. El-Gammal, H. Mazhar, J. S. Cotton, C. Shefski, J. Pietralik and C. Y. Ching, Nucl. Eng. Des., 2010, 240, 1589-1598.

27 W. Tao and S. Shigeru, Metals, 2018, 8, 627.

28 E. V. Senatore, W. Taleb and J. Owen, Wear, 2018, 404, 143152.

29 H. Mansoori, R. Mirzaee, F. Esmaeilzadeh, A. Vojood and A. S. Dowrani, Eng. Failure Anal., 2017, 82, 16-25.

30 G. Svenningsen and J. Kvarekvål, Corrosion, 2018, 10383, 10964.

31 A. Jenkins and I. Gilbert, Corrosion, 2012, 10383, 1275.

32 C. Chen, M. Lu, D. Sun, Z. Zhang and W. Chang, Corrosion, 2005, 61, 594-601. 